more, and nearly $60 \%$ at least once a year. Though the differing methods of the data collection render comparisons across these studies difficult, our findings suggest that the use of the placebo is increasing. The former study recorded actual prescriptions and was limited to actual placebo pills or saline, while we studied the self reports of healthcare providers, and, in certain circumstances, paracetamol and vitamin pills were also counted as placebos.

\section{Implications}

Some have advocated banning the clinical use of placebos because of the deception involved in administration and the possible harm to the doctorpatient relationship. ${ }^{23}$ Others have suggested guidelines for the proper use of placebos without violating the patient's trust and autonomy. ${ }^{5-7}$ Our study shows that administration of placebos for clinical purposes continues. Clearly, wider recognition of the practice, and debate about its implications, are needed. Further investigations into the extent and nature of use should be conducted, particularly in a clinical context where the placebo's effect may differ from that found in randomised controlled trials. ${ }^{8}$ Moreover, though Israeli medicine is taught and practised as elsewhere in the Western world, similar surveys in other geographical areas may reveal cross cultural differences.

Contributors: UN had the original idea for the study and compiled the data. Both authors jointly developed the questionnaire. PL wrote most of the article and is guarantor.

Funding: None.

Competing interests: None declared.

Ethical approval: Not required.

\section{What is already known on this topic}

No study has recently attempted to assess the use of placebos in clinical settings

Placebos may be effective in some areas, but their use raises ethical issues

\section{What this study adds}

Three in five clinicians continue to use placebos

Clinicians believe that some patients benefit from placebo treatment

The role of placebo treatment, its mechanisms, and its ethics need to be the subject of wider medical education and debate

1 Goodwin JS, Goodwin JM, Vogel AV. Knowledge and use of placebos by house officers and nurses. Ann Intern Med 1979;91:106-10

2 De Deyn PP, d'Hooge R. Placebos in clinical practice and research.J Med Ethics 1996;22:140-6.

3 Hill J. Placebos in clinical care: for whose pleasure? Lancet 2003;362:254.

4 Hrobjartsson A, Gotzsche PC. Is the placebo powerless? An analysis of clinical trials comparing placebo with no treatment. $N$ Engl J Med 2001;344:1594-602.

5 Brown WA. Placebo as a treatment for depression. Neuropsychopharmacology 1994;10:265-9.

6 Lione A. Ethics of placebo use in clinical care. Lancet 2003;362:999.

7 Lichtenberg P, Heresco-Levy U, Nitzan U. The ethics of the placebo in clinical practice. J Med Ethics (in press).

8 Vase L, Riley JL, Price DD. A comparison of placebo effects in clinical analgesic trials versus studies of placebo analgesia. Pain 2002; 99:443-52.

9 Hyland ME. Using the placebo response in clinical practice. Clin Med 2003;3:347-50.

(Accepted 13 August 2004)

doi $10.1136 / \mathrm{bmj} .38236 .646678 .55$

\title{
Are written responses to some referrals to a general haematology clinic acceptable?
}

\section{Allison Tso, Lucy Harris, Tim Littlewood}

Department of

Haematology,John Radcliffe Hospital,

Oxford OX3 9DU

Allison Tso

senior house officer in medicine

Lucy Harris

medical student

Tim Littlewood

consultant

haematologist

Correspondence to: T Littlewood

tim.littlewood@

orh.nhs.uk

BMJ 2004;329:946-7
Each year about 1000 patients are referred to the department of haematology in Oxford. Excluded from this number are referrals for problems related to coagulation, which are seen at the Oxford Haemophilia Centre. We wondered whether a written reply to the general practitioner would provide the same quality of healthcare advice more quickly, and with less inconvenience to the patients, than seeing patients in a hospital outpatient clinic.

\section{Methods and results}

One consultant (TL) received 274 letters of referral between 1 November 2001 and 1 January 2003 and wrote a response to 121 (table). We subsequently sent each of the general practitioners who had received a written response a questionnaire (box) with a copy of their original referral letter and a copy of the written reply.

TL sent written responses if the patient neither required further investigation (such as a bone marrow biopsy) nor treatment that would better be done in the haematology department and if no evidence indicated a serious underlying illness, such as malignancy. For

\section{Questionnaire}

Was a written reply offering advice rather than an outpatient appointment acceptable to you? Yes/No Was the advice given helpful to you? Yes/No

Would you be satisfied with a written response in the future if thought appropriate? Yes/No

Do you know if the patient was satisfied with a written response? Yes/No

Invited other comments

example, a mild macrocytosis (mean cellular volume less than $105 \mathrm{fl}$ ) without accompanying cytopenia was the commonest referral for which TL sent a written response. In all patients, the blood film had been examined (and was normal apart from the mild macrocytosis) and advice was offered about checking for possible causes of macrocytosis (including vitamin B-12 or folate deficiency, liver disease, hypothyroidism, drug related causes, and excess alcohol consumption), if these factors

This article was posted on bmj.com on 1 October 2004: http://bmj.com/ cgi/doi/10.1136/bmj.38253.703553.F7 
Reason for referral of 274 patients to a consultant in a haematological department and whether they were sent a written response or seen in an outpatient clinic

\begin{tabular}{lcc} 
Reason for referral & $\begin{array}{c}\text { Written } \\
\text { response }\end{array}$ & $\begin{array}{c}\text { Seen in } \\
\text { outpatient clinic }\end{array}$ \\
\hline Raised mean cell volume (no cytopenia) & 30 & 1 \\
\hline Iron or vitamin B-12 deficiency & 34 & 3 \\
\hline Polycythaemia & 4 & 20 \\
\hline Leucopenia & 14 & 4 \\
\hline Raised platelet count & 10 & 5 \\
\hline Haemoglobinopathy & 9 & 0 \\
\hline Thrombocytopenia & 7 & 9 \\
\hline Paraprotein related & 4 & 37 \\
\hline Normochromic normocytic anaemia & 5 & 12 \\
\hline Miscellaneous & 4 & 10 \\
\hline Myelodysplasia & 0 & 16 \\
\hline Lymphoma & 0 & 16 \\
\hline Chronic lymphatic leukaemia & 0 & 10 \\
\hline Investigation of lymphadenopathy & 0 & 6 \\
\hline Acute leukaemia & 0 & 2 \\
\hline Chronic myeloid leukaemia & 0 & 2 \\
\hline Total & $\mathbf{1 2 1}$ & $\mathbf{1 5 3}$
\end{tabular}

had not already been considered. TL recommended that the full blood count be repeated in three to six months and that the patient be re-referred if either the macrocytosis had worsened or a cytopenia had developed.

We received anonymous replies from 104/121 questionnaires. Of the 104 responses, 101 said that a written response was acceptable and 103 said that the information given was helpful. All the respondents said that they would be satisfied with a written response in the future when deemed appropriate. Seventy two patients were thought to be happy with a written response. The remainder had not been asked for their opinion.

We also received 39 favourable comments, but one general practitioner felt that patients expect to see a consultant after a referral and another felt that anyone needing an explanation of any sort of haematological problem should see a specialist rather than having it explained in writing.

\section{Comment}

Selected referrals to a general haematology clinic can be managed by written responses rather than patients being seen in a hospital clinic. The pattern of referrals

\section{What is already known on this topic}

No published studies of a similar nature could be found

\section{What the study adds}

Some patients with abnormalities suggestive of a haematological disorder do not need to be seen in outpatient clinics but can be well managed by a written response to the referring doctor

to the clinic was similar to those referred to Leeds General Infirmary in 1989.

A weakness of this study is the lack of analysis of the patients' opinions about a written response. Most general practitioners felt that the patient was happy with the strategy, but any follow up study should ascertain this more formally.

We learnt from the small number of unfavourable comments to include a final sentence in all letters stating that if the referring doctor or the patient was not happy with the written response that they would be seen in the clinic. Since completing this study, five of the patients have been re-referred, of whom three were then reviewed in the outpatients clinic.

We are conscious that this system worked well in one discipline, in one hospital in the United Kingdom. Although it may not be applicable in other settings, this system should at least be applicable to some other haematology departments.

We thank all the general practitioners who completed and returned questionnaires.

Contributors: TL wrote the written responses and was primarily responsible for writing the paper. AT and LH did the audit. TL is guarantor.

Funding: No additional funding.

Competing interests: None declared.

Ethical approval: Not needed.

1 Wright D, Smith G, Norfolk D, Child A. Sources and types of referral to a haematology department. Health Trends 1992;24:145-8.

(Accepted 11 August 2004)

doi 10.1136/bmj.38253.703553.F7
We are now inviting all authors who want to submit a paper to the $B M J$ to do so via the web (http://submit.bmj.com).

We have introduced Benchpress, our new web based manuscript tracking system, with the aim of streamlining our processes and providing better, quicker information for authors reviewers, and editors.

Benchpress is a website where authors deposit their manuscripts and editors go to read them and record their decisions. Reviewers' details are also held on the system, and when asked to review a paper reviewers will be invited to access the site to see the relevant paper. The system is secure, protected by passwords, so that authors see only their own papers and reviewers see only those they are meant to.

For authors in particular the system offers several benefits. The system provides all our guidance and forms and allows authors to suggest reviewers for their paper-something we'd like to encourage. Authors get an immediate acknowledgement that their submission has been received, and they can watch the progress of their manuscript. The record of their submission, including editors' and reviewers' reports, remains on the system for future reference.

Anyone with an internet connection and a web browser can use the system.

The system itself offers extensive help, and the BMJ Online Submission Team office is geared up to help authors and reviewers if they get stuck.

Benchpress is accessed via http://submit.bmj.com or via a link from bmj.com 